\title{
Sugarcane bagasse pyrolysis in a carbon dioxide atmosphere with conventional and microwave-assisted heating
}

\author{
Bo-Jhih Lin and Wei-Hsin Chen* \\ Department of Aeronautics and Astronautics, National Cheng Kung University, Tainan, Taiwan
}

\section{Edited by:}

Houzhang Tan, Xi'an Jiaotong

University, China

\section{Reviewed by:}

Jean-Henry Ferrasse, Aix Marseille University, France

Tianju Chen, Chinese Academy of Sciences, China

${ }^{*}$ Correspondence:

Wei-Hsin Chen, Department of Aeronautics and Astronautics, National Cheng Kung University, Tainan 701, Taiwan

e-mail:weihsinchen@gmail.com
Pyrolysis is an important thermochemical method to convert biomass into bio-oil. In this study, the pyrolysis of sugarcane bagasse in a $\mathrm{CO}_{2}$ atmosphere under conventional and microwave-assisted heating is investigated to achieve $\mathrm{CO}_{2}$ utilization. In the microwave pyrolysis, charcoal is used as the microwave absorber to aid in pyrolysis reactions. The results indicate that the yields of pyrolysis products are greatly influenced by the heating modes. In the conventional heating, the prime product is bio-oil and its yield is in the range of $51-54 \mathrm{wt} \%$, whereas biochar is the major product in microwave-assisted heating and its yield ranges from 61 to $84 \mathrm{wt} \%$. Two different absorber blending ratios of 0.1 and 0.3 are considered in the microwave pyrolysis. The solid yield decreases when the absorber blending ratio decreases from 0.3 to 0.1 , while the gas and liquid yields increase. This is attributed to more energy consumed for bagasse pyrolysis at the lower blending ratio. Hydrogen is produced under the microwave pyrolysis and its concentration is between 2 and $12 \mathrm{vol} \%$. This arises from the fact that the secondary cracking of vapors and the secondary decomposition of biochar in an environment with microwave irradiation is easier than those with conventional heating.

Keywords: biomass pyrolysis, bio-oil, biochar, microwave-assisted heating, carbon dioxide utilization

\section{INTRODUCTION}

To date, the increasing concentrations of greenhouse gases (GHGs) in the atmosphere are a remarkable issue. Carbon dioxide has the biggest share of GHG emissions, so it is the most important contributor to the global warming, which has a serious impact on social, environmental, and economic costs (Bilgili, 2012; Chen, 2014). Biomass is regarded as an important renewable fuel because of its short life cycle. Compared to fossil fuels, biomass is abundant, easy to be stored, and carbon neural fuel (Chen et al., 2014). Biomass even acts as an atmospheric $\mathrm{CO}_{2}$ sink if it is associated with the carbon capture and storage (CCS) technology (Chen et al., 2013; Huang et al., 2013; Yin et al., 2013). A variety of thermochemical and biochemical methods have been developed for bioenergy. Pyrolysis is one of the thermochemical methods where biomass is thermally degraded to produce biofuels in the absence of oxidants or in a nitrogen environment. The operating temperature of pyrolysis is normally between 500 and $800^{\circ} \mathrm{C}$ (Carrier et al., 2011; Akhtar and Amin, 2012).

Biochar, bio-oils, and non-condensable gases are three major products from biomass pyrolysis. Biochar has been employed as a feedstock to produce activated carbon, as a fertilizer for soil amendment and carbon sequestration and as a reducing agent for ironmaking (Lee et al., 2010; Srivastava et al., 2013; Yin et al., 2013; Parparita et al., 2014). Bio-oils potentially present valuable liquid fuels, because they are a mixture of about 200 types of major and minor organic compounds; they can be used as the source of some pure chemicals. Bio-oils have also been tested as an alternative wood preservative because they contain a considerable amount of phenolic compounds. Moreover, bio-oils have some advantages in transport, storage, combustion, retrofitting, and flexibility in production and marketing (Asadullah et al., 2007; Carrier et al., 2011; Kim et al., 2012).

The relative amounts of products in a pyrolysis process depend on biomass properties, operating parameters, and pyrolysis types such as slow, intermediate, and fast pyrolysis (Bridgwater, 2012). Mythili et al. (2013) pyrolyzed 25 agricultural wastes in a fixedbed reactor at $450^{\circ} \mathrm{C}$ to produce bio-oils. Their results showed that the volatile matter and cellulose content in biomass played an important role on bio-oil yield. Stefanidis et al. (2014) investigated the pyrolysis of cellulose, xylan, and lignin at $500^{\circ} \mathrm{C}$ in the absence and presence of catalyst using a thermogravimetric analyzer. Among the three constituents, more bio-oil was produced from cellulose pyrolysis. Xylan was decomposed at temperatures lower than $500^{\circ} \mathrm{C}$. At such a high temperature, the vapors from xylan significantly underwent secondary cracking and gave high yields of water, gas products, and coke. The pyrolysis of lignin gave a moderate bio-oil yield, a very low gas yield and a high solid yield. Demiral and Ayan (2011) pyrolyzed grape bagasse in a fixed-bed reactor to investigate the product distribution and find the process conditions for maximizing bio-oil yield. The maximum oil yield was $27.60 \%$ occurred at $550^{\circ} \mathrm{C}$ with the nitrogen flow-rate of $100 \mathrm{~cm}^{3} \mathrm{~min}^{-1}$ and the heating rate of $50^{\circ} \mathrm{C} \mathrm{min}^{-1}$. Guo et al. (2011) studied the pyrolysis of rice husk and the thermal behavior of bio-oil by means of a thermogravimetric analyzer in conjunction with a Fourier transform infrared spectrometer (TGFTIR). The bio-oil yield was $46.36 \%$ and the gas yield was $27 \%$ at 
$520^{\circ} \mathrm{C}$. Their thermogravimetric analysis (TGA) revealed that the bio-oil had a rapid mass loss rate in the temperature range of 25$200^{\circ} \mathrm{C}$ due to its high moisture content. The main components of bio-oil were acetic acid, 1-hydroxy-2-propanone, and ethyl alcohol from the FTIR results. Heo et al. (2010) studied the fast pyrolysis of rice husk in a fluidized bed at different reaction conditions. The optimal pyrolysis temperature for bio-oil production was between 400 and $450^{\circ} \mathrm{C}$. On account of the higher ash content in rice husk than in woody biomass, this led to the catalytic cracking of vapors by the ash during pyrolysis, and the bio-oil yield from the rice husk was lower than those from the woody biomass.

In general, biomass is heated by electric heaters or external burners to perform pyrolysis. Apart from these conventional methods, microwaves have also been developed as an alternative heating source for biomass pyrolysis. Unlike conventional heating where heat is transferred from the surface of the material to its interior through heat conduction and convection, the entire volume of the material is heated in a microwave environment via dielectric heating. More specifically, heat is transferred from the core of the material toward its surface. Because microwave-assisted heating has the merits of internal and rapid heating, large-size samples can be heated to reduce the pretreatment processes of raw materials. Microwave pyrolysis has attracted increasing interests by many researchers (Salema and Ani, 2011; Luque et al., 2012; Zhao et al., 2013).

In a microwave reaction system for pyrolysis, additives or microwave absorbers such as activated carbon, biochar, $\mathrm{SiC}$, metallic oxides, ionic liquids, and sulfuric acid are usually added into biomass to improve the liquid or gas yield or their quality (Chen et al., 2008a; Salema and Ani, 2012; Yin, 2012; Zhao et al., 2012). Zhao et al. (2012) showed that the temperature was a major parameter affecting the performance of microwave pyrolysis. High temperatures favorably increased the gas product. The gas yield increased from 17.69 to $22.27 \mathrm{wt} \%$ and the ratio of fuel gas to total gas product increased from 67.21 to $77.14 \mathrm{vol} \%$ when the temperature increased from 400 to $600^{\circ} \mathrm{C}$. Kuan et al. (2013) investigated the effects of metal-oxides (NiO, $\mathrm{CuO}, \mathrm{CaO}$, and $\mathrm{MgO}$ ) on the microwave pyrolysis of sugarcane bagasse. Their results showed that the liquid yield significantly increased under the addition of either $\mathrm{NiO}$ or $\mathrm{CuO}$; the addition of $\mathrm{CaO}$ and $\mathrm{MgO}$ increased the product gas because they could react with water to produce alkaline aqueous, which facilitated $\mathrm{H}_{2}$ production and increased the gas yield. Salema and Ani (2012) observed that the microwave heating technique was highly effective in pyrolyzing oil palm biomass (fiber and shell). The yields of pyrolysis products were greatly influenced by the microwave absorber (activated carbon). The maximum bio-oil yield from oil palm pyrolysis was exhibited at the biomass-tomicrowave absorber ratio of 1:0.5. Zhao et al. (2013) studied the microwave pyrolysis of wheat straw in a fixed-bed reactor and the effects of both the temperature and the presence of additives $\left(\mathrm{K}_{2} \mathrm{CO}_{3}, \mathrm{Na}_{2} \mathrm{CO}_{3}, \mathrm{CaO}\right)$ on the yields and properties of products. The solid yield decreased with the increase of microwave power during the heating up stage, whereas the trend of gas yield was opposite. The $\mathrm{H}_{2}$ concentration was increased by approximately 20 vol\% when the microwave power increased from 400 to $600 \mathrm{~W}$.
From the above literature review, many studies have been published concerning the characteristics of biomass pyrolysis by conventional or microwave-assisted heating. However, available data are insufficient on the effects of heating model and reaction atmosphere on biomass pyrolysis. Sugarcane bagasse is a common and abundant agricultural waste. This research aims to experimentally examine the pyrolysis behavior of sugarcane bagasse under different heating modes (conventional heating and microwaving heating). Moreover, $\mathrm{CO}_{2}$ will be used as a carrier gas in the course of biomass pyrolysis to evaluate the potential of $\mathrm{CO}_{2}$ utilization in pyrolysis. The obtained results are conducive to the industrial production of biofuels from sugarcane bagasse.

\section{EXPERIMENTAL}

\section{RAW MATERIAL PREPARATION}

Sugarcane bagasse obtained from Taiwan Sugar Corporation in Tainan, Taiwan, was selected as the raw material to be studied. The bagasse was dried in an oven at $105^{\circ} \mathrm{C}$ for $24 \mathrm{~h}$ to remove the moisture in the raw material. Thereafter, the dried bagasse was grinded and sieved to particle sizes of $40-100$ mesh $(=0.12-0.45 \mathrm{~mm})$. Then the prepared bagasse was stored in a desiccator at room temperature until pyrolysis was carried out. The photographs and properties of the bagasse are listed in Table 1.

\section{REACTION SYSTEM AND EXPERIMENTAL PROCEDURE}

The reaction system consisted of a $\mathrm{CO}_{2}$ steel cylinder, a reaction (pyrolysis) unit, a liquid collection unit, a gas treatment unit, and a product gas analysis unit. The $\mathrm{CO}_{2}$ steel cylinder was used to supply $\mathrm{CO}_{2}$ as a carrier gas for providing a pyrolysis environment. The flow-rate of $\mathrm{CO}_{2}$ was controlled at $75 \mathrm{~mL} \mathrm{~min}^{-1}\left(25^{\circ} \mathrm{C}\right)$ by an electronic flow-rate controller (KD-4000) and a readout (Brooks 5850E). In the reaction system, both conventional and

Table 1 | Photography and basic properties of raw sugarcane bagasse.

\begin{tabular}{lc}
\hline Biomass & Sugarcane bagasse \\
\hline Photograph & $0.12-0.45$ (mesh 40-100) \\
& \\
Material size (mm) & 1.34 \\
Proximate analysis (wt\%) & 85.45 \\
Moisture & 11.32 \\
Volatile matter (VM) & 1.89 \\
Fixed carbon (FC) & \\
Ash & 28.36 \\
Fiber analysis (wt\%) & 49.85 \\
Hemicellulose & 14.92 \\
Cellulose & 6.88 \\
Lignin & \\
Other & 39.78 \\
Elemental analysis (wt\%, dry basis) & 5.32 \\
C & 0.37 \\
H & 50.98 \\
$\mathrm{~N}$ &
\end{tabular}


microwave-assisted heating were performed. In the experiments with conventional heating, the reaction unit comprised a quartz reaction tube ( $45 \mathrm{~mm}$ i.d.) and a tube furnace. The bagasse $(20 \mathrm{~g}$ ) was placed in the quartz tube and the tube was situated in the tube furnace. The schematics of the pyrolysis reactors with conventional heating and microwave-assisted heating are shown in Figure 1. In the experiments with microwave-assisted heating, the reaction unit was made up of a quartz tube $(36.5 \mathrm{~mm}$ i.d.), a K-type thermocouple, a chamber, a magnetron, and a power controller. The biomass was packed at the bottom of the reaction tube wherein the thermocouple was installed at the center. The thermocouple was shielded by an alumina tube to prevent microwave absorption by any metallic part of the thermocouple (Chen et al., 2008b). A watt-hour meter was installed in the reaction unit to measure the inlet electricity of the unit at a frequency of $1 \mathrm{~Hz}$. The supplied power was recorded by a recorder (computer). It should be illustrated that only part of the supplied power was delivered to the solid for heating. Charcoal was used as the microwave absorber. The charcoal was also grinded and sieved to particle sizes of $40-100$ mesh $(=0.12-0.45 \mathrm{~mm})$. The bagasse $(10 \mathrm{~g})$ was blended with charcoal ( 1 or $3 \mathrm{~g})$ and the reaction temperature was fixed at $550^{\circ} \mathrm{C}$; that is, the absorber (or charcoal) blending ratio is 0.1 or 0.3 . The liquid collection unit was composed of a conical flask for bio-oil collection. In the gas treatment unit, a condenser $\left(\right.$ at $5^{\circ} \mathrm{C}$ ) and a dryer wherein the commercial silica gel pellets were packed were used to treat the product gas. Considering the gas analysis unit, a gas chromatography (SRI 310C TCD), and a gas analyzer (Fuji ZRJF5Y23-AERYR-YKLYYCY-A) were utilized. The volumetric concentrations of $\mathrm{CO}, \mathrm{CO}_{2}$, and $\mathrm{CH}_{4}$ were detected by the gas analyzer, while the $\mathrm{H}_{2}$ concentration was measured by the gas chromatography.

\section{RAW MATERIAL AND PRODUCT ANALYSIS}

The raw material was analyzed through proximate, fiber, elemental (ultimate), and thermogravimetric analyses. The proximate analysis was performed in accordance with the standard procedure of American Society for Testing and Materials (ASTM). In the fiber analysis, hemicellulose, cellulose, and lignin were measured following the method adopted in a previous study (Chen et al., 2010). The elemental analysis was carried out using an elemental analyzer (Elementar Vario EL III). The TGA was carried out via a thermogravimetric analyzer (TG, PerkinElmer Diamond TG/DTA). In the TGA, $5 \mathrm{mg}$ of the biomass was analyzed in the temperature range of $25-800^{\circ} \mathrm{C}$ where the volumetric flow-rate of nitrogen was $100 \mathrm{~mL}$ $\min ^{-1}$ and the heating rate was $20^{\circ} \mathrm{C} \mathrm{min}^{-1}$. When the temperature reached $105^{\circ} \mathrm{C}$, it was held for $10 \mathrm{~min}$ to completely remove moisture. After the experiments of pyrolysis were achieved, the solid, liquid, and gas yields were determined. The solid and liquid yields are defined as:

$$
\begin{aligned}
\text { Solid yield }(\mathrm{wt} \%) & =\frac{\text { weight of solid residue }}{\text { weight of raw biomass }} \times 100 \\
\text { Liquid yield }(\mathrm{wt} \%) & =\frac{\text { weight of condensed liquid }}{\text { weight of raw biomass }} \times 100
\end{aligned}
$$

After getting the solid and liquid yields, the gas yield was obtained by difference; that is, gas yield $=100-$ solid
A

Tube furnace

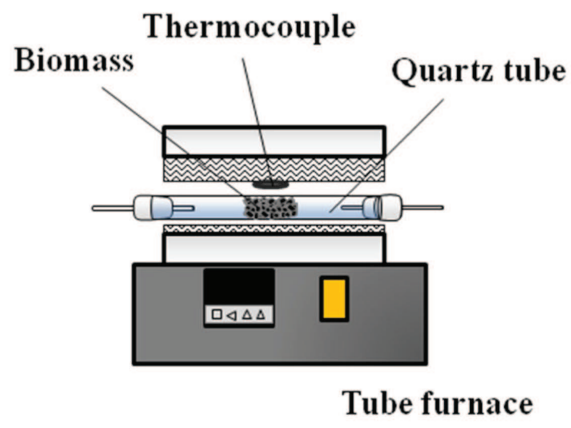

B Microwave reactor

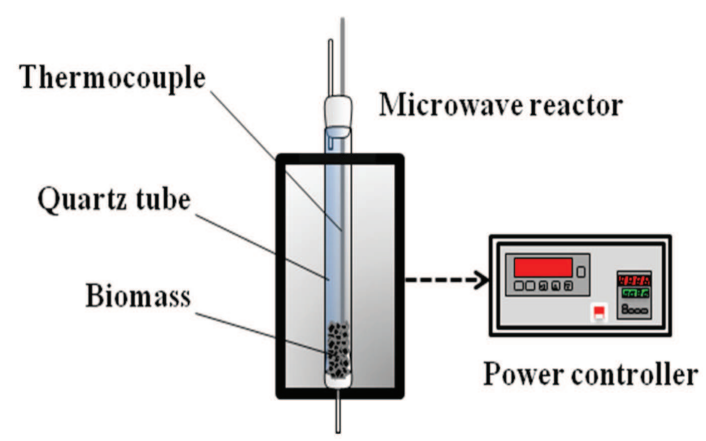

FIGURE 1 | Schematics of pyrolysis reactors with (A) conventional heating and (B) microwave-assisted heating.

yield - liquid yield. To ensure the experimental quality, prior to performing experiments the adopted instruments were periodically calibrated. Moreover, the relative error of the data was $<5 \%$ and the data discussed in the present study were the average results.

\section{RESULTS AND DISCUSSION THERMOGRAVIMETRIC ANALYSIS}

The distributions of TGA and the derivative thermogravimetric (DTG) analyses of raw bagasse are displayed in Figure 2. The distributions reveal that the thermal degradation of the biomass mainly occurs at temperatures between 200 and $400^{\circ} \mathrm{C}$. It was reported (Yang et al., 2007; Chen et al., 2012) that the decomposition temperatures of hemicellulose, cellulose, and lignin were in the ranges of $200-315,315-400$, and $160-900^{\circ} \mathrm{C}$, respectively, stemming from their inherent difference in lignocellulosic structure. It follows that the first peak exhibited at $319^{\circ} \mathrm{C}$ (Figure 2) is due to the thermal decomposition of hemicellulose in raw bagasse, while the second peak observed at $366^{\circ} \mathrm{C}$ is owing to the thermal degradation of cellulose. When the temperature is higher than $400^{\circ} \mathrm{C}$, the continuous and slow decomposition of the biomass can be explained by lignin decomposition in a high temperature environment. The TGA curve indicates that over $78 \mathrm{wt} \%$ of bagasse is thermally degradated when the reaction temperature is beyond 


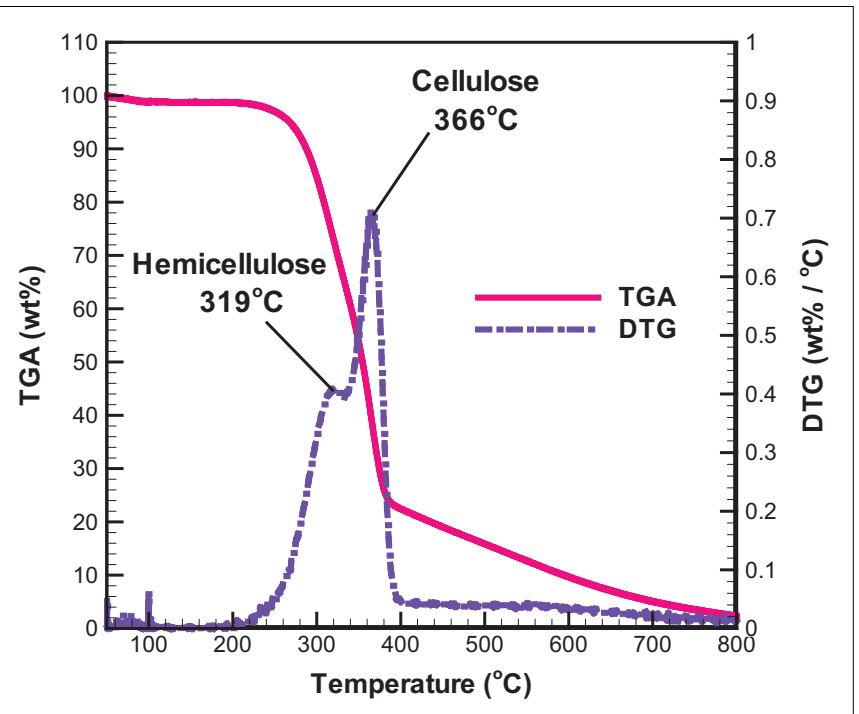

FIGURE 2 | Distributions of TGA and DTG of raw sugarcane bagasse

$400^{\circ} \mathrm{C}$. It follows that the bagasse pyrolysis should be performed at temperatures higher than $400^{\circ} \mathrm{C}$. For this reason, bagasse pyrolysis at three reaction temperatures of 450,500 , and $550^{\circ} \mathrm{C}$ are taken into account in the present study.

\section{PYROLYSIS UNDER CONVENTIONAL HEATING}

The three-phase product yields from bagasse pyrolysis under conventional heating at temperatures of 450,500 , and $550^{\circ} \mathrm{C}$ are presented in Figure 3. It is clear that increasing temperature decreases the solid yield; specifically, the solid yield decreases from 25.9 to $22.5 \mathrm{wt} \%$ when the pyrolysis temperature increases from 450 to $550^{\circ} \mathrm{C}$. The liquid yield is in the range of $51-54 \mathrm{wt} \%$, which is much higher than the solid yield, revealing that the bio-oil is the main product from the bagasse pyrolysis. A higher temperature causes a more violent thermal decomposition reaction. However, it is noted that the maximum liquid yield is $53.3 \mathrm{wt} \%$, which occurs at $500^{\circ} \mathrm{C}$ rather than at $550^{\circ} \mathrm{C}$. This is possibly attributed to the pronounced secondary cracking of bio-oil once the reaction temperature is as high as $550^{\circ} \mathrm{C}$ (Demiral and Ayan, 2011). The elemental analyses of bio-oils from bagasse pyrolyzes at the three temperatures are given in Table 2. The weight percentages of carbon and hydrogen in bio-oils are in the ranges of 29.2031.68 and 8.76-9.08 wt $\%$, respectively, revealing that the content of atomic $\mathrm{H}$ is much higher than that of atomic $\mathrm{C}$, resulting from water contained in the bio-oils.

With attention focused on the gas yield, Figure 3 depicts that the gas yield increases with increasing temperature and ranges from 21.3 to $25.9 \mathrm{wt} \%$, which is close to the solid yield. The increased gas yield is also due to the intensified secondary cracking of bio-oil, which converts partial liquid product into the gas product. The gaseous species from the pyrolysis under conventional heating mainly consisted of $\mathrm{CO}_{2}, \mathrm{CO}$, and $\mathrm{CH}_{4}$. The relative concentrations (vol\%) of $\mathrm{CO}_{2}, \mathrm{CO}$, and $\mathrm{CH}_{4}$ in the product gas with time are shown in Figure 4 . $\mathrm{CO}_{2}$ released in the course of biomass pyrolysis is partly caused by hemicellulose decomposition at

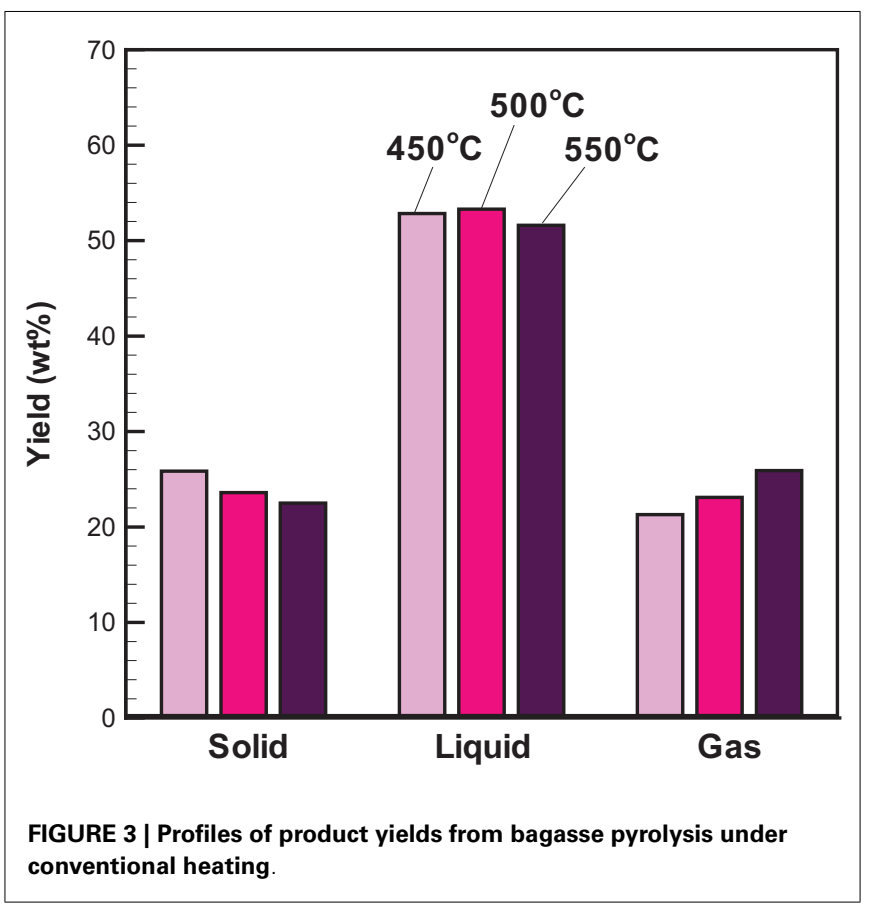

Table 2 | Elemental analyses of bio-oils from bagasse pyrolysis under conventional heating

\begin{tabular}{lcccc}
\hline Temperature $\left({ }^{\circ} \mathbf{C}\right)$ & \multicolumn{4}{c}{ Elemental analysis (wt\%) } \\
\cline { 2 - 5 } & C & H & N & O (by diff.) \\
\hline 450 & 29.20 & 9.08 & 0.48 & 61.24 \\
500 & 28.93 & 8.95 & 0.63 & 61.50 \\
550 & 31.68 & 8.76 & 0.46 & 59.11 \\
\hline
\end{tabular}

low temperatures $\left(<500^{\circ} \mathrm{C}\right)$ and by lignin at high temperatures $\left(>500^{\circ} \mathrm{C}\right.$ ) (Ciuta et al., 2014). CO is released from the cracking of carbonyl $(\mathrm{C}-\mathrm{O}-\mathrm{C})$ and carboxyl $(\mathrm{C}=\mathrm{O})$ stemming from hemicellulose pyrolysis (Ciuta et al., 2014). The CO concentration is approximately $19-21$ vol\% when the reaction time reaches $30 \mathrm{~min}$. The release of $\mathrm{CH}_{4}$ is caused by the cracking of methoxyl-O- $\mathrm{CH}_{3}$, and the methoxyl is sensitive to the reaction temperature (Yang et al., 2007; Xin et al., 2013). At the reaction time of $30 \mathrm{~min}$, the $\mathrm{CH}_{4}$ concentration increases from 4.55 to 9.82 vol\% when the reaction temperature increases from 450 to $550^{\circ} \mathrm{C}$. On account of more energy required to break the $\mathrm{R}-\mathrm{CH}_{3}$ bond and to form $\mathrm{CH}_{4}$ (Xin et al., 2013), the appearance of $\mathrm{CH}_{4}$ is later than the other gases.

\section{PYROLYSIS UNDER MICROWAVE-ASSISTED HEATING}

Figure 5 shows the profiles of product yields from bagasse pyrolysis at $550^{\circ} \mathrm{C}$ and two different absorber blending ratios under microwave-assisted heating. As a whole, the solid, liquid, and gas yields are in the ranges of 61.9-83.2, 14.4-22.0, and 2.4-16.1 wt\%, respectively. The solid yield is substantially higher than the liquid and gas yields, implying that the behavior of bagasse pyrolysis under microwave-assisted heating is inherently different from that 


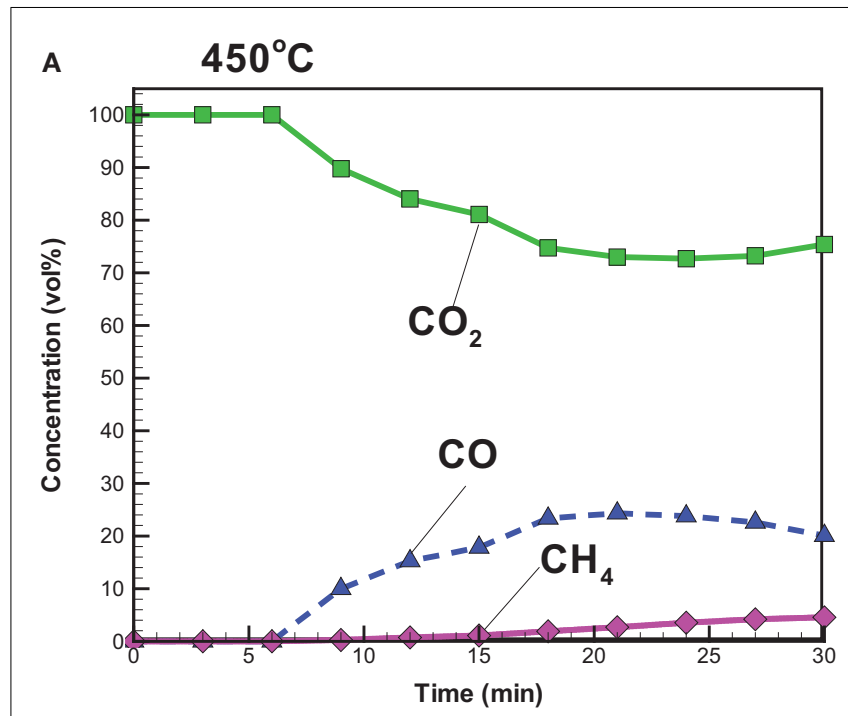

B

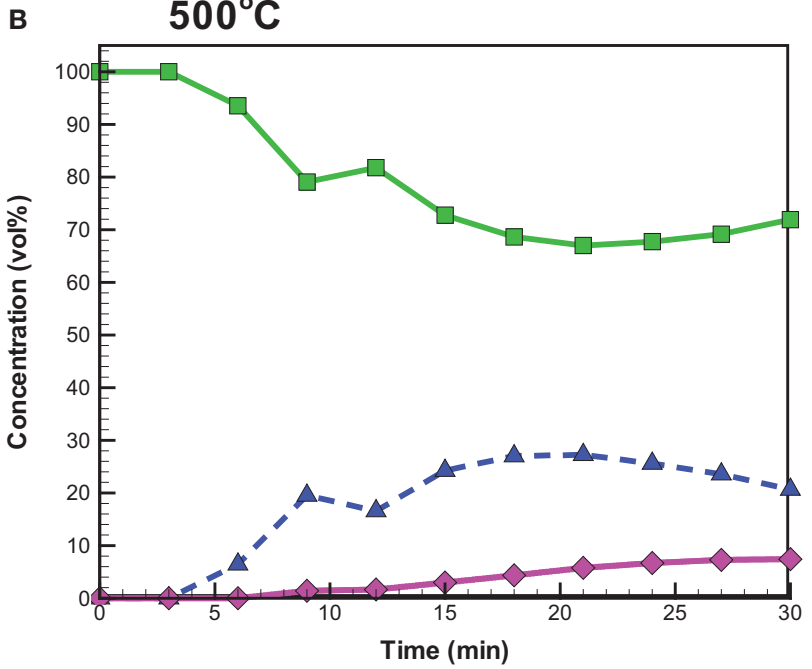

C $550^{\circ} \mathrm{C}$

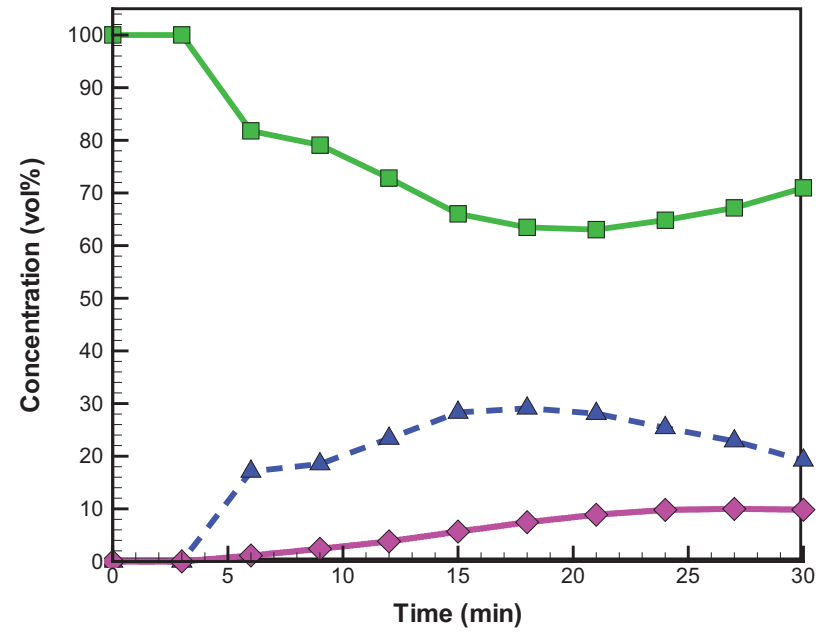

FIGURE 4 | Temporal distributions of $\mathrm{CO}, \mathrm{CO}_{2}$, and $\mathrm{CH}_{4}$ concentrations from bagasse pyrolysis under conventional heating at (A) 450, (B) 500, and (C) $550^{\circ} \mathrm{C}$

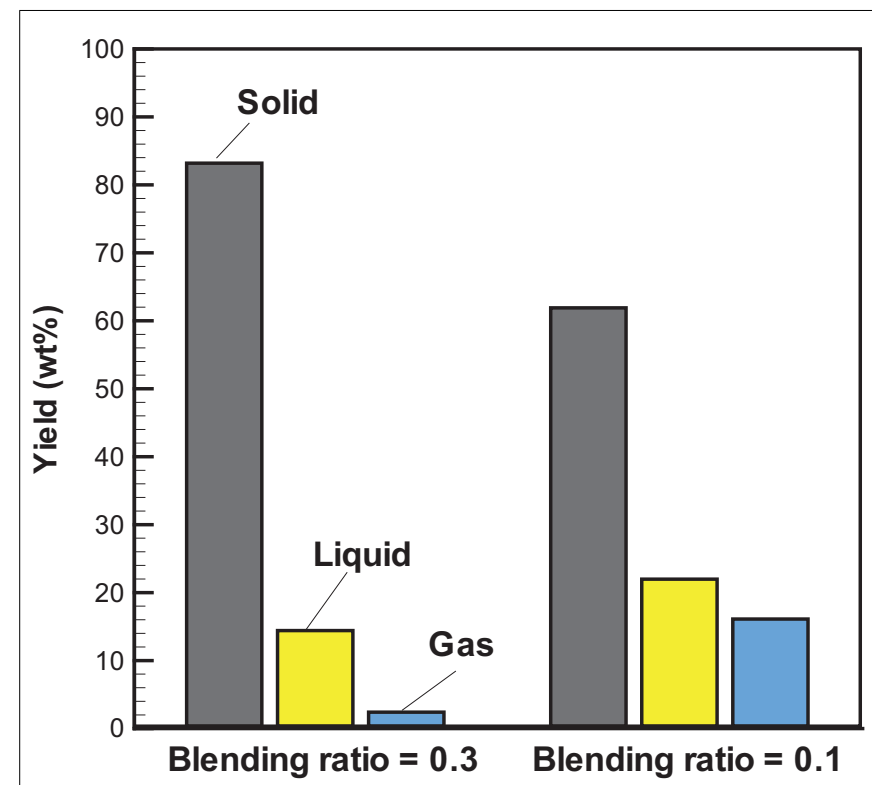

FIGURE 5 | Profiles of product yields from bagasse pyrolysis under microwave-assisted heating at $550^{\circ} \mathrm{C}$ and the absorber blending ratios of 0.3 and 0.1

under conventional heating. Alternatively, the solid, liquid, and gas yields have different behaviors at different absorber blending ratios. The solid yield decreases when the blending ratio decreases from 0.3 to 0.1 , whereas the gas and liquid yields increase. Figure 6 demonstrates the temporal distributions of supplied power and energy of the microwave reactor. It can be seen that power oscillation is relatively pronounced at the higher charcoal blending ratio $(=0.3)$ within 13 min after the onset of experiment, as a consequence of more microwaves absorbed by the absorber. In contrast, more energy is required for bagasse pyrolysis at the lower blending ratio $(=0.1)$. Specifically, corresponding to absorber blending ratios of 0.3 and 0.1 at $550^{\circ} \mathrm{C}$ for $30 \mathrm{~min}$, the amounts of supplied energy are 423 and $534 \mathrm{~kJ}$, respectively. The higher energy absorption at the blending ratio of 0.1 may be the reason causing the lower solid yield. It has been pointed out (Zhao et al., 2014) that an increase in supplied power of microwave reactor decreased the solid yield and increased the gas and liquid yields. In the present study, the same trends in the solid, liquid, and gas yields are observed. The elemental analyses of the bio-oils at the two operating conditions are listed in Table 3. It is noted that the carbon content in the bio-oil at the blending ratio of 0.3 is $9.18 \%$, while it is $20.43 \%$ at the blending ratio of 0.1 , which is closer to the results of the conventional heating (Table 2). The lower carbon content at the ratio of 0.3 can be explained by the lower microwave power supplied. This results in a lower extent of pyrolysis and more water is contained in the liquid phase.

Figure 7 shows the temporal distribution of $\mathrm{CO}_{2}, \mathrm{CO}, \mathrm{H}_{2}$, and $\mathrm{CH}_{4}$ from bagasse pyrolysis under microwave-assisted heating. A comparison to the pyrolysis with conventional heating suggests that bagasse pyrolysis with microwave irradiation at the blending 


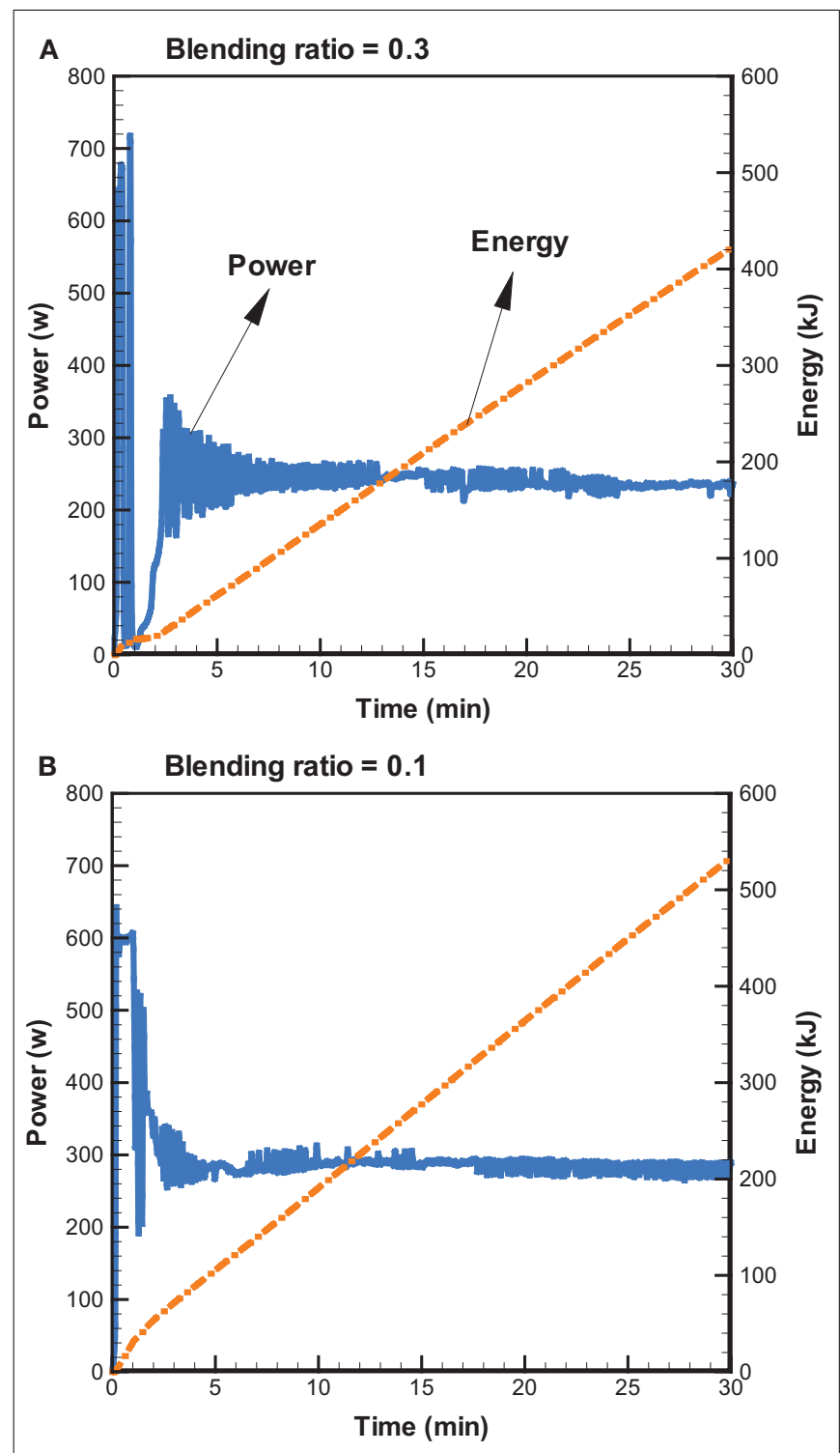

FIGURE 6 |Temporal distributions of supplied microwave power and energy at $550^{\circ} \mathrm{C}$ and the blending ratios of (A) 0.3 and (B) 0.1 .

Table 3 | Elemental analyses of bio-oil from bagasse pyrolysis under microwave-assisted heating

\begin{tabular}{lrrrr}
\hline Charcoal/raw ratio & \multicolumn{4}{c}{ Elemental analysis (wt\%) } \\
\cline { 2 - 5 } & \multicolumn{1}{c}{ C } & H & N & O (by diff.) \\
\hline 0.3 & 9.18 & 11.41 & 0.23 & 79.18 \\
0.1 & 20.43 & 8.79 & 0.41 & 70.38 \\
\hline
\end{tabular}

ratio of 0.3 has a higher $\mathrm{CO}_{2}$ concentration and lower $\mathrm{CO}$ and $\mathrm{CH}_{4}$ concentrations. Again, this is due to the lower microwave power supplied. Unlike the pyrolysis under conventional heating, $\mathrm{H}_{2}$ is produced under the microwave-assisted heating and the $\mathrm{H}_{2}$ concentration is in the range of $2-12$ vol\%. With conventional heating, the secondary pyrolysis involves the following reactions (Dai et al., 2000; Zhao et al., 2014):

$$
\begin{aligned}
& \operatorname{Tar}_{(\mathrm{g})} \rightarrow \mathrm{CH}_{4(\mathrm{~g})}+\mathrm{H}_{2} \mathrm{O}_{(\mathrm{g})}+\mathrm{C}_{\mathrm{m}} \mathrm{H}_{\mathrm{n}(\mathrm{g})}+\mathrm{H}_{2(\mathrm{~g})} \\
& \mathrm{CH}_{4(\mathrm{~g})}+\mathrm{H}_{2} \mathrm{O}_{(\mathrm{g})} \leftrightarrow 3 \mathrm{H}_{2(\mathrm{~g})}+\mathrm{CO}_{(\mathrm{g})}, \Delta \mathrm{H}^{0}=206.1 \mathrm{kJmol}^{-1} \\
& \mathrm{C}_{(\mathrm{s})}+\mathrm{H}_{2} \mathrm{O}_{(\mathrm{g})} \leftrightarrow \mathrm{H}_{2(\mathrm{~g})}+\mathrm{CO}_{(\mathrm{g})}, \Delta \mathrm{H}^{0}=132 \mathrm{kJmol}^{-1} \\
& \mathrm{CO}_{(\mathrm{g})}+\mathrm{H}_{2} \mathrm{O}_{(\mathrm{g})} \leftrightarrow \mathrm{H}_{2(\mathrm{~g})}+\mathrm{CO}_{2(\mathrm{~g})}, \Delta \mathrm{H}^{0}=-41.5 \mathrm{kJmol}^{-1} \\
& \mathrm{C}_{(\mathrm{s})}+\mathrm{CO}_{2(\mathrm{~g})} \leftrightarrow 2 \mathrm{CO}_{(\mathrm{g})}, \Delta \mathrm{H}^{0}=173 \mathrm{kJmol}^{-1} \\
& \mathrm{CH}_{4(\mathrm{~g})} \leftrightarrow 2 \mathrm{H}_{2(\mathrm{~g})}+\mathrm{C}_{(\mathrm{s})}, \Delta \mathrm{H}^{0}=75.6 \mathrm{kJmol}^{-1} \\
& \mathrm{CH}_{4(\mathrm{~g})}+\mathrm{CO}_{2(\mathrm{~g})} \leftrightarrow 2 \mathrm{H}_{2(\mathrm{~g})}+2 \mathrm{CO}(\mathrm{g}), \Delta \mathrm{H}^{0}=260.5 \mathrm{kJmol}^{-1} \\
& \mathrm{C}_{\mathrm{m}} \mathrm{H}_{\mathrm{n}(\mathrm{g})}+2 \mathrm{nH}_{2} \mathrm{O}_{(\mathrm{g})} \rightarrow[2 \mathrm{n}+(\mathrm{m} / 2)] \mathrm{H}_{2(\mathrm{~g})}+\mathrm{nCO}_{2(\mathrm{~g})} \\
& \mathrm{C}_{\mathrm{m}} \mathrm{H}_{\mathrm{n}(\mathrm{g})}+\mathrm{nH}_{2} \mathrm{O}_{(\mathrm{g})} \rightarrow[2 \mathrm{n}+(\mathrm{m} / 2)] \mathrm{H}_{2(\mathrm{~g})}+\mathrm{nCO}_{(\mathrm{g})}
\end{aligned}
$$

Equation 7 can be ignored because of the requirement for high reaction temperatures $\left(>800^{\circ} \mathrm{C}\right)$. In microwave pyrolysis, however, due to the special nature of microwave-assisted heating, the secondary cracking pathways of volatiles are markedly different from those of conventional pyrolysis (Demiral and Ayan, 2011). Moreover, charcoal and produced biochar and bio-oil absorb microwaves strongly, so the secondary cracking of vapors and secondary decomposition of biochar under microwave irradiation are easier than those under conventional heating. This results in the formation of $\mathrm{H}_{2}$. The changing trend of $\mathrm{H}_{2}$ can be used to characterize the degree of secondary pyrolysis. Dai et al. (2000) point out that the higher the $\mathrm{H}_{2}$ production, the more drastic the secondary reactions are.

\section{EFFECT OF HEATING MODE}

Temporal temperature distributions in the initial period of the two different heating modes are shown in Figure 8. It can be seen that the growth in temperature for sugarcane bagasse pyrolysis with microwave-assisted heating is faster than that with conventional heating. Specifically, around $2 \mathrm{~min}$ is required for temperature reaching the steady state under microwave-assisted heating, whereas it requires approximately $6 \mathrm{~min}$ under conventional heating. Figure 9 shows the product yields from bagasse pyrolysis under the two heating modes where $10 \mathrm{~g}$ of bagasse was blended with $1 \mathrm{~g}$ of charcoal and the reaction temperature was $550^{\circ} \mathrm{C}$. The profiles between the conventional heating and the microwaveassisted heating are significantly different from each other. The major product under conventional heating is bio-oil and its yield is $52.8 \mathrm{wt} \%$; biochar under microwave-assisted heating is the main product and the yield is $61.9 \mathrm{wt} \%$. The elemental analyses of the bio-oils from the two heating modes are given in Table 4. The carbon content of the bio-oil under conventional heating $(27.83 \mathrm{wt} \%)$ is higher than that under microwave-assisted heating $(20.43 \mathrm{wt} \%)$, stemming from the stronger secondary cracking of vapors in the latter. Though the liquid yield (22 wt\%) under microwave heating is relatively low, it is consistent with past studies (Dominguez et al., 2007; Salema and Ani, 2011, 2012; Huang et al., 2013; Zhao et al., 2013) in that the liquid yield was in the range of $10-30 \mathrm{wt} \%$ from biomass pyrolysis under microwave-assisted heating. 


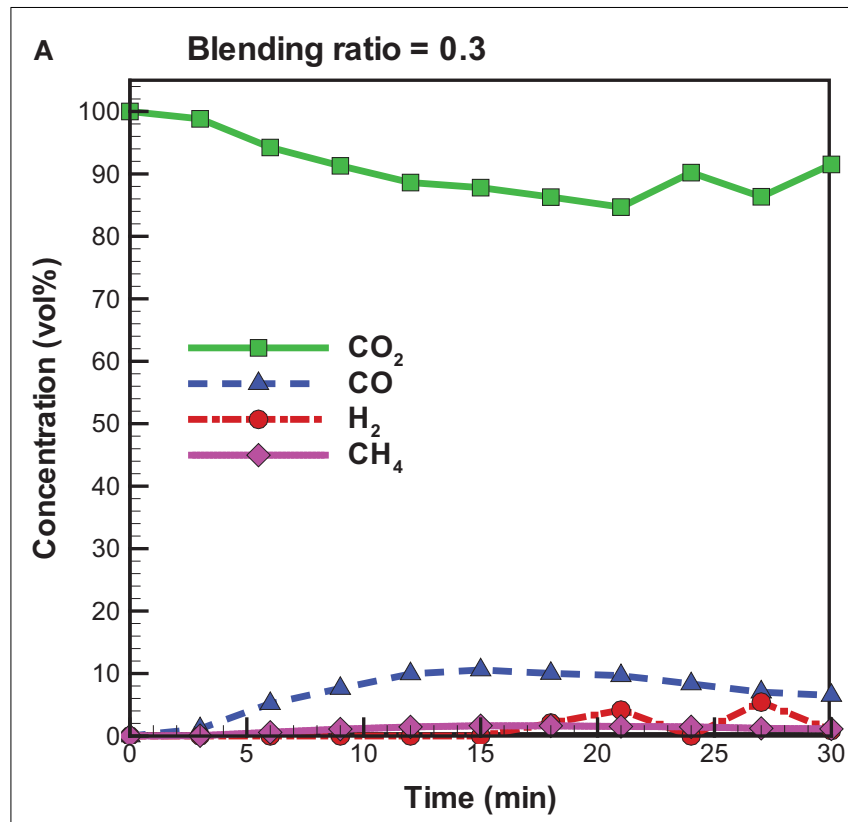

B $\quad$ Blending ratio $=0.1$

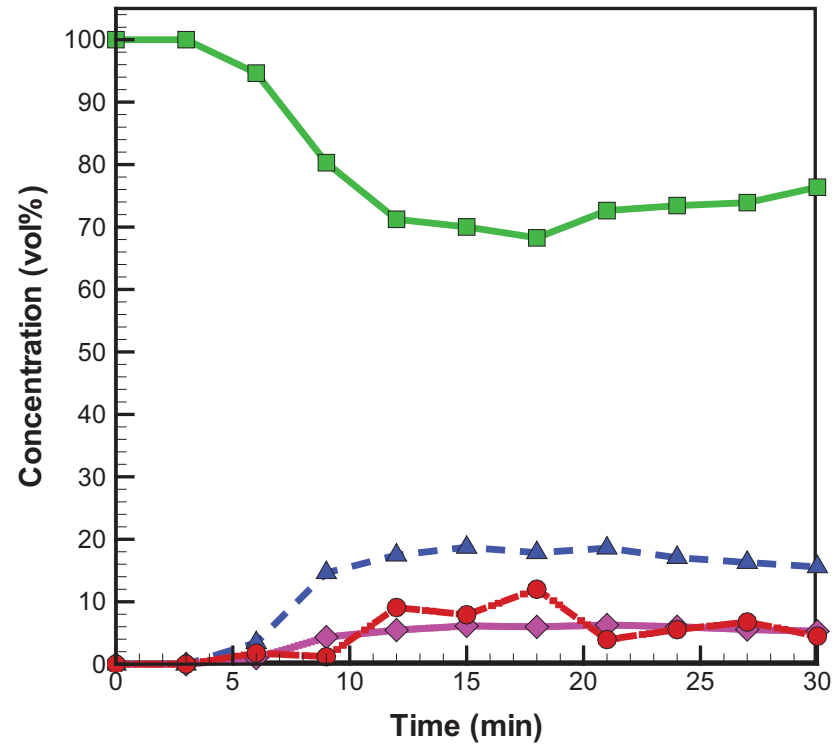

FIGURE 7 | Temporal distributions of $\mathrm{CO}, \mathrm{CO}_{2}$, and $\mathrm{CH}_{4}$ concentrations from bagasse pyrolysis under microwave-assisted heating at $550^{\circ} \mathrm{C}$ and the blending ratios of $(A) 0.3$ and $(B) 0.1$.

In our study, sugarcane bagasse pyrolyzed in a $\mathrm{CO}_{2}$ atmosphere was performed, but the biomass pyrolysis in a $\mathrm{N}_{2}$ atmosphere was absent. Therefore, the biomass pyrolyzes in the two different atmospheres could not be compared with each other. Nevertheless, Zhang et al. (2011) investigated the fast pyrolysis of corn cob in a fluidized bed reactor under five different gas atmosphere $\left(\mathrm{N}_{2}, \mathrm{CO}_{2}, \mathrm{CO}, \mathrm{CH}_{4}\right.$, and $\left.\mathrm{H}_{2}\right)$, and found that the product yields in $\mathrm{CO}_{2}$ or $\mathrm{N}_{2}$ atmospheres were similar to each other. However, the pyrolysis in the $\mathrm{CO}_{2}$ atmospheres gave the lowest $\mathrm{CO}_{2}$ selectivity, and the produced bio-oils contained more acetic acid

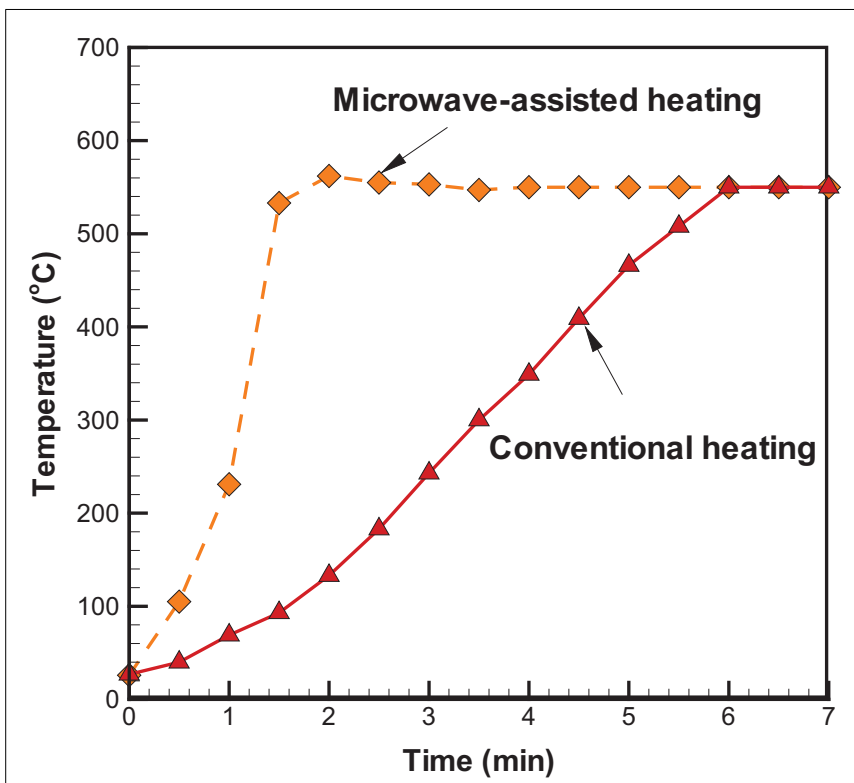

FIGURE 8 | Temporal temperature distributions in the initial period of two different heating modes at $550^{\circ} \mathrm{C}$ and the absorber blending ratio of 0.1 .

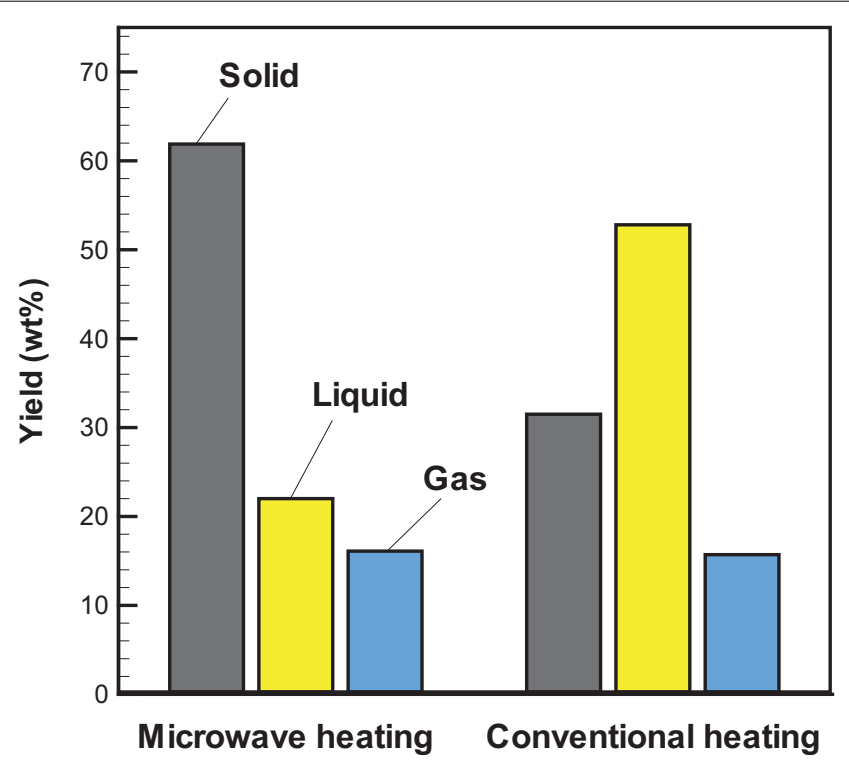

FIGURE 9 | Profiles of product yields from bagasse pyrolysis under conventional and microwave-assisted heating at $550^{\circ} \mathrm{C}$ and the absorber blending ratio of $\mathbf{0 . 1}$

than in the other atmospheres. These could be explained by two possible reasons: (1) the carrier gas $\mathrm{CO}_{2}$ reacted with the active volatiles produced in the pyrolysis process and formed acetic acid; (2) $\mathrm{CO}_{2}$ partly reacted with the solid residue and formed acetic acid. Accordingly, biomass pyrolysis in $\mathrm{CO}_{2}$ and $\mathrm{N}_{2}$ atmospheres in association with microwave-assisted heating deserves investigation in the future. 
Table 4 | Elemental analyses of bio-oil from bagasse pyrolysis under different heating modes.

\begin{tabular}{lcccc}
\hline Heating mode & \multicolumn{4}{c}{ Elemental analysis (wt\%) } \\
\cline { 2 - 5 } & C & H & N & O (by diff.) \\
\hline Conventional heating & 27.83 & 8.78 & 0.38 & 63.02 \\
Microwave-assisted heating & 20.43 & 8.79 & 0.41 & 70.38
\end{tabular}

Operation conditions: $10 \mathrm{~g}$ bagasse blended with $1 \mathrm{~g}$ charcoal at $550^{\circ} \mathrm{C}$.

Table 5 |The operating conditions and product yields from bagasse pyrolysis under different heating modes.

\begin{tabular}{|c|c|c|c|c|c|c|}
\hline \multirow[t]{2}{*}{$\begin{array}{l}\text { Heating } \\
\text { mode }\end{array}$} & \multicolumn{3}{|c|}{ Operating conditions } & \multicolumn{3}{|c|}{$\begin{array}{l}\text { Product } \\
\text { yields (wt \%) }\end{array}$} \\
\hline & $\begin{array}{l}\text { Temper- } \\
\text { ature } \\
\left({ }^{\circ} \mathrm{C}\right)\end{array}$ & $\begin{array}{l}\text { Duration } \\
\text { (min) }\end{array}$ & $\begin{array}{l}\text { Absorber } \\
\text { blending } \\
\text { ratio }\end{array}$ & Solid & Bio-oil & Gas $^{a}$ \\
\hline \multirow{4}{*}{$\begin{array}{l}\text { Conventional } \\
\text { heating }\end{array}$} & 400 & 30 & 0 & 25.9 & 52.9 & 21.2 \\
\hline & 450 & 30 & 0 & 23.6 & 53.3 & 23.1 \\
\hline & 500 & 30 & 0 & 22.5 & 51.6 & 25.9 \\
\hline & 550 & 30 & 0.1 & 31.5 & 52.8 & 15.7 \\
\hline \multirow{2}{*}{$\begin{array}{l}\text { Microwave- } \\
\text { assisted } \\
\text { heating }\end{array}$} & 550 & 30 & 0.3 & 83.2 & 14.4 & 2.4 \\
\hline & 550 & 30 & 0.1 & 61.9 & 22.0 & 16.1 \\
\hline
\end{tabular}

${ }^{a}$ By difference.

\section{CONCLUSION}

The pyrolysis of sugarcane bagasse in a $\mathrm{CO}_{2}$ atmosphere with conventional and microwave-assisted heating has been investigated in the present study. The operating conditions and product yields from bagasse pyrolysis under the two heating modes are summarized in Table 5. The conclusions are drawn as follows.

1. For bagasse pyrolysis with conventional heating at 450,500 , and $550^{\circ} \mathrm{C}$, the liquid yield is over $50 \mathrm{wt} \%$ and the maximum yield is $53.3 \mathrm{wt} \%$. An increase in reaction temperature decreases the solid and liquid yields, but increases the gas yield, possibly due to the pronounced secondary cracking of bio-oil.

2. Different from pyrolysis under conventional heating at $550^{\circ} \mathrm{C}$, biochar is the prime product for bagasse pyrolyzed under microwave-assisted heating. Increasing the absorber blending ratio reduces the energy supplied by the reactor; however, the liquid and gas yields are lower as well. The results appear that the blending ratio of 0.1 gives a better operation than of 0.3 . Nevertheless, more energy is required to produce liquid and gas products.

3. Hydrogen is found in the product gas when microwave-assisted heating is performed where its concentration is in the range of 2-12 vol\%, whereas it is not detected when conventional heating is employed. The generation of $\mathrm{H}_{2}$ is due to the intensified secondary cracking of vapors and secondary decomposition of biochar in a microwave irradiation environment.

\section{ACKNOWLEDGMENTS}

The authors gratefully acknowledge the financial support of the Ministry of Science and Technology, Taiwan, R.O.C., under contract NSC 102-2221-E-006-288-MY3 for this study.

\section{REFERENCES}

Akhtar, J., and Amin, N. S. (2012). A review on operating parameters for optimum liquid oil yield in biomass pyrolysis. Renew. Sustain. Energ. Rev. 16, 5101-5109. doi:10.1016/j.rser.2012.05.033

Asadullah, M., Rahman, M. A., Ali, M. M., Rahman, M. S., Motin, M. A., Sultan, M. B., et al. (2007). Production of bio-oil from fixed bed pyrolysis of bagasse. Fuel 86, 2514.2520. doi:10.1016/j.fuel.2007.02.007

Bilgili, F. (2012). The impact of biomass consumption on $\mathrm{CO}_{2}$ emissions: cointegration analyses with regime shifts. Renew. Sustain. Energ. Rev. 16, 5349-5354. doi:10.1016/j.rser.2012.04.021

Bridgwater, A. V. (2012). Review of fast pyrolysis of biomass and product upgrading. Biomass Bioenergy 38, 68-94. doi:10.1016/j.biombioe.2011.01.048

Carrier, M., Hugo, T., Gorgens, J., and Knoetze, H. (2011). Comparison of slow and vacuum pyrolysis of sugar cane bagasse. J. Anal. Appl. Pyrolysis 90, 18-26. doi:10.1016/j.jaap.2010.10.001

Chen, M. Q., Wang, J., Zhang, M. X., Chen, M. G., Zhu, X. F., Min, F. F., et al. (2008a). Catalytic effects of eight inorganic additives on pyrolysis of pine wood sawdust by microwave heating. J. Anal. Appl. Pyrolysis 82, 145-150. doi:10.1016/j.jaap.2008.03.001

Chen, W. H., Jheng, J. G., and Yu, A. B. (2008b). Hydrogen generation from a catalytic water gas shift reaction under microwave irradiation. Int. J. Hydrogen Energy 33, 4789-4797. doi:10.1016/j.ijhydene.2008.08.039

Chen, W. H. (2014). $\mathrm{CO}_{2}$ conversion for syngas production in methane catalytic partial oxidation. J. $\mathrm{CO}_{2}$ Utilization 5, 1-9. doi:10.1016/j.jcou.2013.11.001

Chen, W. H., Lu, K. M., Liu, S. H., Tsai, C. M., Lee, W. J., and Lin, T. C. (2013). Biomass torrefaction characteristics in inert and oxidative atmospheres at various superficial velocities. Bioresour. Technol. 146, 152-160. doi:10.1016/j.biortech. 2013.07.064

Chen, W. H., Tu, Y. J., and Sheen, H. K. (2010). Impact of dilute acid pretreatment on the structure of bagasse for producing bioethanol. Int. J. Energy Res 34, 265-274. doi:10.1002/er.1566

Chen, W. H., Wu, Z. Y., and Chang, J. S. (2014). Isothermal and non-isothermal torrefaction characteristics and kinetics of microalga Scenedesmus obliquus CNWN. Bioresour. Technol. 155, 245-251. doi:10.1016/j.biortech.2013.12.116

Chen, W. H., Ye, S. C., and Sheen, H. K. (2012). Hydrothermal carbonization of sugarcane bagasse via wet torrefaction in association with microwave heating. Bioresour. Technol. 118, 195-203. doi:10.1016/j.biortech.2012.04.101

Ciuta, S., Patuzzi, F., Baratieri, M., and Castaldi, M. J. (2014). Biomass energy behavior study during pyrolysis process by intraparticle gas sampling. J. Anal. Appl. Pyrolysis 108, 316-322. doi:10.1016/j.jaap.2014.04.012

Dai, X., Wu, C., Li, H., and Chen, Y. (2000). The fast pyrolysis of biomass in CFB reactor. Energy Fuels 14, 552-557. doi:10.1021/ef9901645

Demiral, I., and Ayan, E. A. (2011). Pyrolysis of grape bagasse: effect of pyrolysis conditions on the product yields and characterization of the liquid product. Bioresour. Technol. 102, 3946-3951. doi:10.1016/j.biortech.2010.11.077

Dominguez, A., Menendez, J. A., Fernandez, Y., Pis, J. J., Nabais, J. M. V., Carrott, P. J. M., et al. (2007). Conventional and microwave induced pyrolysis of coffee hulls for the production of a hydrogen rich fuel gas. J. Anal. Appl. Pyrolysis 79, 128-135. doi:10.1016/j.jaap.2006.08.003

Guo, X. J., Wang, S. R., Wang, Q. I., Guo, Z. G., and Luo, Z. Y. (2011). Properties of bio-oil from fast pyrolysis of rice husk. Chin. J. Chem. Eng. 19, 116-121. doi:10.1016/j.biortech.2012.03.116

Heo, S. H., Park, H. J., Dong, J. I., Park, S. H., Kim, S., Suh, D. J., et al. (2010). Fast pyrolysis of rice husk under different reaction conditions. J. Ind. Eng. Chem. 16, 27-31. doi:10.1016/j.jiec.2010.01.026

Huang, H. B., Aisyah, L., Leung, Y. C., and Kwong, C. W. (2013). Chemical looping combustion of biomass-derived syngas using ceria-supported oxygen carriers. Bioresour. Technol. 140, 385-391. doi:10.1016/j.biortech.2013.04.070

Kim, K. H., Jeong, H. S., Kim, J. Y., Han, G. S., Choi, I. G., and Choi, J. W. (2012). Evaluation of the antifungal effects of bio-oil prepared with lignocellulosic biomass using fast pyrolysis technology. Chemosphere 89, 688-693. doi:10.1016/j.chemosphere.2012.06.010 
Kuan, W. H., Huang, Y. F., Chang, C. C., and Lo, S. L. (2013). Catalytic pyrolysis of sugarcane bagasse by using microwave heating. Bioresour. Technol. 146, 324-329. doi:10.1016/j.biortech.2013.07.079

Lee, J. W., Hawkins, B., Day, D. M., and Ceicosky, D. C. (2010). Sustainability: the capacity of smokeless biomass pyrolysis for energy production, global carbon capture and sequestration. Energy Environ. Sci. 3, 1695-1705. doi:10.1039/ c004561f

Luque, R., Menendez, J. A., Arenillas, A., and Cot, J. (2012). Microwave-assisted pyrolysis of biomass feedstocks: the way forward. Energy Environ. Sci. 5, 5481-5488. doi:10.1039/clee02450g

Mythili, R., Venkatachalam, P., Subramanian, P., and Uma, D. (2013). Characterization of bioresidues for biooil production through pyrolysis. Bioresour. Technol. 138, 71-78. doi:10.1016/j.biortech.2013.03.161

Parparita, E., Brebu, M., Uddin, M. A., Yanik, J., and Vasile, C. (2014). Pyrolysis behaviors of various biomasses. Polym. Degrad. Stab. 100, 1-9. doi:10.1016/j. polymdegradstab.2014.01.005

Salema, A. A., and Ani, F. N. (2011). Microwave induced pyrolysis of oil palm biomass. Bioresour. Technol. 102, 3388-3395. doi:10.1016/j.biortech.2010.09.115

Salema, A. A., and Ani, F. N. (2012). Microwave-assisted pyrolysis of oil palm shell biomass using an overhead stirrer. J. Anal. Appl. Pyrolysis 96, 162-172. doi:10.1016/j.jaap.2012.03.018

Srivastava, U., Kawatra, S. K., and Eisele, T. C. (2013). Production of pig iron by utilizing biomass as a reducing agent. Int. J. Miner. Process 119, 51-57. doi:10.1016/j.minpro.2012.12.008

Stefanidis, S. D., Kalogiannis, K. G., Iliopoulou, E. F., Michailof, C. M., Pilavachi, P. A., and Lappas, A. A. (2014). A study of lignocellulosic biomass pyrolysis via the pyrolysis of cellulose, hemicellulose and lignin. J. Anal. Appl. Pyrolysis 105, 143-150. doi:10.1016/j.jaap.2013.10.013

Xin, S., Yang, H., Chen, Y., Wang, X., and Chen, H. (2013). Assessment of pyrolysis polygeneration of biomass based on major components: product characterization and elucidation of degradation pathways. Fuel 113, 266-273. doi:10.1016/j.fuel.2013.05.061

Yang, H., Yan, R., Chen, H., Lee, D. H., and Zheng, C. (2007). Characteristics of hemicellulose, cellulose and lignin pyrolysis. Fuel 86, 1781-1788. doi:10.1016/j. fuel.2006.12.013
Yin, C. (2012). Microwave-assisted pyrolysis of biomass for liquid biofuels production. Bioresour. Technol. 120, 279-284. doi:10.1016/j.biortech.2012.06.016

Yin, R., Liu, R., Mei, Y., Fei, W., and Sun, X. (2013). Characterization of bio-oil and biochar obtained from sweet sorghum bagasse fast pyrolysis with fractional condensers. Fuel 112, 96-104. doi:10.1016/j.fuel.2013.04.090

Zhang, H., Xiao, R., Wang, D., He, G., Shao, S., Zhang, J., et al. (2011). Biomass fast pyrolysis in a fluidized bed reactor under $\mathrm{N}_{2}, \mathrm{CO}_{2}, \mathrm{CO}, \mathrm{CH}_{4}$ and $\mathrm{H}_{2}$ atmospheres. Bioresour. Technol. 102, 4258-4264. doi:10.1016/j.biortech.2010.12.075

Zhao, X., Wang, M., Liu, H., Li, L., Ma, C., and Song, Z. (2012). A microwave reactor for characterization of pyrolyzed biomass. Bioresour. Technol. 104, 673-678. doi:10.1016/j.biortech.2011.09.137

Zhao, X., Wang, M., Liu, H., Zhao, C., Ma, C., and Song, Z. (2013). Effect of temperature and additives on the yields of products and microwave pyrolysis behaviors of wheat straw. J. Anal. Appl. Pyrolysis 100, 49-55. doi:10.1016/j.jaap.2012.11.016

Zhao, X., Wang, W., Liu, H., Ma, C., and Song, Z. (2014). Microwave pyrolysis of wheat straw: product distribution and generation mechanism. Bioresour. Technol. 158, 278-285. doi:10.1016/j.biortech.2014.01.094

Conflict of Interest Statement: The authors declare that the research was conducted in the absence of any commercial or financial relationships that could be construed as a potential conflict of interest.

Received: 10 October 2014; accepted: 21 January 2015; published online: 04 February 2015.

Citation: Lin B-J and Chen W-H (2015) Sugarcane bagasse pyrolysis in a carbon dioxide atmosphere with conventional and microwave-assisted heating. Front. Energy Res. 3:4. doi: 10.3389/fenrg.2015.00004

This article was submitted to Bioenergy and Biofuels, a section of the journal Frontiers in Energy Research.

Copyright (C) 2015 Lin and Chen. This is an open-access article distributed under the terms of the Creative Commons Attribution License (CC BY). The use, distribution or reproduction in other forums is permitted, provided the original author(s) or licensor are credited and that the original publication in this journal is cited, in accordance with accepted academic practice. No use, distribution or reproduction is permitted which does not comply with these terms. 